\title{
LAS INTELIGENCIAS MÚLTIPLES EN LAS REPRESENTACIONES SOCIALES EN LA EDUCACIÓN DE LOS ESTUDIANTES DE LA PRIMERA INFANCIA
}

\section{MULTIPLE INTELLIGENCES IN SOCIAL REPRESENTATIONS IN EARLY CHILDHOOD EDUCATION}

\section{AS INTELIGÊNCIAS MÚLTIPLAS NAS REPRESENTAÇÕES SOCIAIS NA EDUCAÇÃO DOS ESTUDANTES DA PRIMEIRA INFÂNCIA}

Ferdy Carina Arguello Muñoz ferdycarina@gmail.com Corporación Universitaria del Caribe -CECAR Montería- Colombia

Gustavo Velásquez Quintana gustavovel@gmail.com

Fundación Universitaria UniGermana Bogotá -Colombia

Ángela María Arrieta Fontalvo angelaarrietafvo@hotmail.com Corporación Universitaria del Caribe -CECAR Montería-Colombia

Diagramación

Sindy Catherine Charcas Ibarra

Fotografia portada Santiago Ardila Acero

Encuentre este artículo en:

http://revistas.uniminuto.edu/index.php/IYD

Para citar este artículo / To cite this article

Arguello, F., Velásquez, G. \& Arrieta, Á. (2021). Las inteligencias múltiples en las representaciones sociales en la educación de los estudiantes de la primera infancia. Inclusión \& Desarrollo, 8 (1), pp 38-47
Fecha de recepción: 25 de agosto de 2020 Fecha de aceptación: 6 de noviembre de 2020 Fecha de publicación: 1 de enero de 2021 


\section{RESUMEN}

El compromiso de los docentes es formar infantes con iniciativa, sentido crítico y creativo, con capacidad para solucionar problemas. Algunos, en cambio, analizan y resuelven problemas matemáticos, elaboran mapas conceptuales, desarrollan habilidades sonoras, entre otras. Para el desarrollo del proyecto se optó por utilizar el enfoque de investigación cualitativa el cual permite comprender el complejo mundo de la experiencia vivida desde el punto de vista de las personas que la viven. Como conclusiones los docentes se deben involucrar cada día en el proceso educativo, las inteligencias múltiples, saber cómo estimularlas en el aula; lo que ayudaría al infante a desarrollar su potencial y su desarrollo integral; es importante que el docente trabaje en mejorar el aprendizaje; darle más oportunidades al alumno y que desarrolle su talento mediante las actividades propuestas.

Palabras Claves: inteligencia, primera infancia, representaciones sociales, innovación, estrategias de enseñanza y aprendizaje, infancia.

\section{ABSTRACT}

\section{ABSTRACT}

The commitment of teachers is to train children with initiative, critical and creative sense, capable of solving problems. Some, on the other hand, analyze and solve mathematical problems, elaborate conceptual maps, develop sound skills, among others. For the development of the project it was chosen to use the qualitative research approach which allows to understand the complex world of the experience lived from the point of view of the people who live it. As conclusions teachers should be involved every day in the educational process, multiple intelligences, know how to stimulate them in the classroom; which would help the child to develop their potential and their integral development; it is important for the teacher to work on improving learning; to give the student more opportunities and to develop his or her talent through the proposed activities. childhood.

Keywords: intelligence, early childhood, social representations, innovation, teaching and learning strategies,

\section{SUMÀRIO}

O compromisso dos docentes é formar infantes com iniciativa, sentido crítico e criativo, com capacidade para solucionar problemas. Alguns, ao contrário, analisam e resolvem problemas matemáticos, elaboram mapas conceituais, desenvolvem habilidades sonoras, entre outras. Para o desenvolvimento do projeto optou-se por utilizar a abordagem de pesquisa qualitativa que permite compreender o complexo mundo da experiência vivida do ponto de vista das pessoas que a vivem. Como conclusões os docentes devem se envolver diariamente no processo educativo, as inteligências múltiplas, saber como estimulá-las na sala de aula; o que ajudaria ao infante a desenvolver seu potencial e seu desenvolvimento integral; é importante que o docente trabalhe para melhorar a aprendizagem; dar mais oportunidades ao aluno e desenvolver o seu talento através das actividades propostas.

Palavras chave: inteligência, primeira infância, representações sociais, inovação, estratégias de ensino e aprendizagem, infancia. 


\section{Introducción}

Los programas de enseñanza predominantes que se desarrollan en las aulas se basan en el trabajo de sólo dos inteligencias fundamentales: la inteligencia Lingüística/Verbal y la inteligencia Lógico/ Matemática, relacionadas, ambas, con las áreas instrumentales, dando una mínima importancia al resto de inteligencias. Es por ello que, para lograr el objetivo de transformar la educación tradicional en una de inteligencias múltiples hay que partir de un trabajo en equipo en el que intervengan los profesores, estudiantes y la propia institución. Proyecto que la comunidad educativa, ha venido desarrollando pero que se requiere de mejoras en su estructura académica.

Del mismo modo la Inteligencia es la capacidad y aptitud de un organismo humano para reaccionar, adaptándose ante nuevas situaciones, partiendo de experiencias pasadas. Desde la filosofía, la psicología, la biología y la neurociencia cognitiva la definición va desde la muy científica la inteligencia es lo que miden los test, y se puede definir como la capacidad para resolver problemas, capacidad al medio y las circunstancias nuevas, capacidad creativa, capacidad para establecer relaciones sociales, capacidad cognitiva y capacidad general; la inteligencia se relaciona con la capacidad intelectual ya sea en términos de capacidad de juicio, asociación o de desarrollo de pensamiento abstracto.

Para definir cada ámbito de la inteligencia, Gardner (1998) estudió el desarrollo de habilidades en los niños y la forma en que se descomponían las diferentes capacidades y tipos de inteligencia. Por otro lado Howard Gardner en su libro, inteligencias múltiples (2016), propone una redefinición de la inteligencia convirtiéndola en un potencial psico-biológico, donde es decisiva la influencia del ambiente en el cual se desarrolla el individuo, sus estilos cognitivos, la disposición para resolver problemas y crear productos. Fundamentalmente, propone maneras diferentes de ser inteligentes (Gardner, 2016). Gardner (1998) afirma: "Los niños demuestran habilidades en las diversas inteligencias a través de la adquisición que hacen de los diversos sistemas simbólicos. A medida que avanza el desarrollo se representa cada inteligencia acompañada de un sistema simbólico".

Siguiendo a Gardner, (1994) la inteligencia como una capacidad y la convierte en una destreza a desarrollar concluyendo "una inteligencia que implica la habilidad necesaria para resolver problemas o para elaborar productos que son importantes en un contexto cultural o en una comunidad determinada". Afirma que la inteligencia es dinámica, siempre crece, se mejora y se amplia.

En el ejercicio docente desarrollado en la Instituto Técnico Primera Infancia se tuvo la oportunidad de conocer de cerca la situación problemática que se vive cotidianamente en el proceso de enseñanza de los contenidos de las diferentes áreas del conocimiento. Las dificultades pedagógicas y metodológicas que afrontan los docentes para estimular la participación activa y la adquisición de los nuevos conocimientos parecen ser insuficientes, traduciéndose en bajos niveles de apropiación de estos conocimientos, lo cual, a su vez, se ven reflejadas en los talleres que son el resultado de las aplicaciones a los estudiantes.

Es importante que los docentes generen actividades pedagógicas, innovadoras, lúdicas, llamativas y motivadoras a los niños y niñas en la construcción por la sociedad para incentivar la lectura, el lenguaje, cantos, los juegos de palabras, relatos de cuentos y de poesías. "A medida que manipulan y se familiarizan con los libros de imágenes, los niños y niñas 
comienzan a descubrir que las ilustraciones en las figuras bidimensionales parecidas a la realidad, representan la realidad" (Cárdenas \& Gómez, 2014). Con este trabajo los niños y las niñas comienzan a identificar su personalidad, su realidad, representaciones de la sociedad, se ejecuta y desarrolla el aprendizaje y la comunicación; esto es fundamental para su crecimiento, madurez y para fortalecer las habilidades y potencialidades propias de su edad. La Inteligencia múltiple es un sistema para desarrollar la inteligencia y se puede incluir en el modelo pedagógico que realiza grandes aportes a la primera infancia en el campo de la educación.

\section{Representaciones sociales}

Las representaciones sociales nacen de la psicología social con el propósito de explicar y tratar de entender como desde lo individual toman curso las representaciones propias que al ser compartidas genera unas aproximaciones al pensamiento colectivo. Anaya (2002) expone que Moscovici plantea la teoría de las representaciones sociales. Moscovici fue el creador del concepto de representaciones sociales, expone particularidades de esta teoría y nuevos objetivos de estudio, que son el pensamiento social incorporado en cada una de las personas, considera Moscovici que la sociedad contemporánea las variantes de pensamiento social son cualitativamente distintas a las de otro tipo de sociedades.

Ahora bien, en la medida que no aborda de frente ni explica la pluralidad de formas de organización del pensamiento, aunque todas sean sociales, la noción de representación pierde nitidez. Quizás haya que buscar ahí otra de las razones de su abandono: Los antropólogos se vuelven hacia el estudio de los mitos; los sociólogos hacia el estudio de las ciencias; los lingüistas hacia el estudio de la lengua y su dimensión semántica, etcétera.
Con el fin de darle un significado determinado, es indispensable hacerlo abandonar su papel de categoría general, que concierne al conjunto de producciones, a la vez intelectuales y sociales. Estimamos que por ese camino se la puede singularizar, separándola de la cadena de términos similares (Moscovici, 1979, p. 28). La representación social es una modalidad particular del conocimiento es un corpus organizado de conocimiento, se integra a un grupo o en una relación cotidiana de intercambios, liberan los poderes de su imaginación (Moscovici 1979). Es el conocimiento de sentido común, su objetivo es comunicar, sentirse del ambiente social y el intercambio de comunicaciones del grupo social. Moscovici transforma la perspectiva de Durkheim (1858-1917) quien en el campo de la Sociología estudia las religiones primitivas como el toteismo, llegando a plantear la teoría de las representaciones colectivas en 1898.

Desde la perspectiva de Moscovici (1979), no existe separación entre el universo individual y el social, sino ambas realidades se integran; sostiene que el individuo se constituye y se encuentra en una realidad material y social, donde internaliza las representaciones al mismo tiempo que participa en su construcción, encontrándose en el límite entre la elaboración del concepto y la percepción.

En los primeros planteamientos de Moscivici; sostiene que la representación social "es una Organización de imágenes y de lenguaje porque recorta y simboliza actos y situaciones que son o se convierten en comunes". Considera que es "una modalidad particular del conocimiento, cuya función es la elaboración de los comportamientos y la comunicación entre los individuos". Es una "preparación para la acción "[...] en que remodela y reconstituye los elementos del medio en el que el comportamiento debe tener lugar" (Moscovici 1979). 
Unsegundoaspecto es que las representaciones operan como sistema de información o esquemas mentales que las personas elaboran para comprender y dar sentido al mundo y poder comunicarse con los demás, sin que sea impuesta externamente por el colectivo.

Moscovici, (1979) Explica que "Si bien la realidad de las representaciones Sociales es fácil de capturar, el concepto no lo es", dado los múltiples aspectos que entran en acción, tales como los procesos cognitivos individuales y colectivos, los modelos de comportamientos aceptados socialmente, las formas y redes de comunicación, los contextos sociales, culturales e históricos que se viven. En consecuencia, la teoría de las representaciones sociales procura entender el conocimiento que circula en forma espontánea y cotidiana, el cual se caracteriza porque se encuentra en permanente proceso de hacerse.

Las representaciones sociales es la manera como los grupos sociales, haciendo uso de lenguaje, construyen el conocimiento necesario para comunicarse y entender la vida cotidiana por medio de valores, opiniones, creencias y normas para relacionarse entre sí. Moscovici (1979), máximo representante de la teoría expresa que: "La representación social es una modalidad particular cuya función es la elaboración de los comportamientos y la comunicación entre los individuos, Es también un corpus organizado de conocimientos y una de las actividades psíquicas gracias a las cuales los hombres hacen inteligible la realidad física y social, se integran en un grupo o en la relación cotidiana liberan los poderes de su imaginación".

\section{La Infancia}

De acuerdo a Gardner, (1998) la inteligencia múltiple es importante en el infante porque el individuo nace con un potencial que viene marcado por el componente genético, el individuo posee unas destrezas y ese mismo individuo tiene otras inteligencias y hace que cada persona tenga un perfil intelectual único según sus inteligencias dominantes y no dominantes.

Hoy en día se reconoce que la infancia responde a una categoría construida socialmente, por ese motivo, los cambios en la mirada sobre ella se continúan produciendo y poder brindar aportes desde la mirada de los futuros profesionales enriquece el estado de la cuestión (Gonza \& Chumacero, 2019).

\section{Desarrollo de la Infancia en las inteligencias múltiples}

La inteligencia múltiple está relacionada con la enseñanza y la formación del infante, es por eso que hoy en día la educación ha planteado reformas para desarrollar las competencias y el fundamento del aprendizaje en el infante. Existe una perspectiva más amplia de la inteligencia múltiple y esta funciona de diferentes maneras en las personas, tiene diferentes mentalidades y poseen diferentes modos de comprensión, de esta manera se determinan otras formas de inteligencias, otra manera de aprender generando en la educación un desafío en enseñar, en aprendizaje y una metodología para aplicar en el niño y la niña.

Por otra parte la creatividad es una pieza clave para el desarrollo de las habilidades en la inteligencia múltiple en la infancia, esta creatividad se origina en la mente, permite que el infante cree algo de la nada o de reproducir con diferentes ideas, destrezas, habilidades, solucionar ciertos problemas o satisfacer ciertos propósitos. Es un sentimiento de libertad que permite una transformación permanente. Es importante que en el aula se aplique por parte del docente, para buscar un mejor aprendizaje en el infante y el alumno reconozca los tipos de inteligencia y memorias creativas. 


\section{Estrategia de enseñanza y aprendizaje}

La estrategia de enseñanza y aprendizaje según Cova (2013) se basa en los procedimientos que el docente debe utilizar de modo inteligente y adaptativo, con el fin de ayudar a los estudiantes a construir sus conocimientos mediante actividades planificadas adecuadamente en base a sus intereses y así poder lograr los objetivos de aprendizaje. Las actividades se planifican en un tiempo determinado, facilitando herramienta a los estudiantes, se motiva el aprendizaje y los nuevos contenidos. Saldaña (2014) define la estrategia de enseñanza y aprendizaje como: Un conjunto de pautas que desarrolla el estudiante para orientar de modo consciente e intencional sus actividades de aprendizaje, siendo producto de sus propias experiencias y recomendaciones del docente sobre cómo hacer más eficiente sus esfuerzos de aprender, constituyendo herramientas fundamentales para la calidad y éxito de las tareas académicas.

Por otra parte Montes (2011) define la estrategia de enseñanza y aprendizaje como:

"Se encuentra involucrada en virtud de la unidad entre enseñar y aprender (...), las cuales pueden ser consideradas como consecuencias integradas más o menos extensas y complejas, de acciones y procedimientos seleccionados y organizados que atendiendo a todos los componentes del proceso, persiguen alcanzar los fines educativos propuestos".

De lo anterior se puede establecer la estrategia de enseñanza y aprendizaje como procedimientos implicados e interconectados en un común objetivo que es el aprendizaje, eficiente, que son organizados con un plan de acción que cumple los requisitos de los programas educativos existentes.

Se concluye con las definiciones de los anteriores autores que la estrategia de enseñanza y aprendizaje son herramientas que organizadas con un plan de acción por el docente basado en métodos, técnicas y recursos le permitirán al estudiante asimilar, internalizar y producir conocimiento de un contenido específico, el educador innova, genera habilidades y competencias particulares para obtener un enfoque claro del estudiante.

\section{Metodología}

Según el libro: "Metodología de la investigación" (Hernández et al., 2010), las "ideas de investigación representan el primer acercamiento a la realidad que se investigará" (p.26). Hasta ese momento, el acercamiento a la realidad puede considerarse objetiva (perspectiva cuantitativa), subjetiva (perspectiva cualitativa) o intersubjetiva (perspectiva mixta). Según los autores citados, el enfoque de investigación cualitativa permite comprender el complejo mundo de la experiencia vivida desde el punto de vista de las personas que la viven. En este enfoque de investigación se utiliza la recolección de datos sin medición numérica para descubrir o afinar preguntas de investigación en el proceso de interpretación.

En cualquier caso, y contrario al enfoque cuantitativo, sus hallazgos dan cuenta de un fenómeno o situación particular, por lo que sus hallazgos no son generalizables (Hernández et al., 2010, p.8). Según Sautu (Sautu, Boniolo \& Dalle, 2005), debido al entorno social y la importancia participativa que tienen las personas en la construcción o transformación de su entorno, esta metodología de investigación permite comprender lo que dicen y hacen las personas en un escenario social y cultural mediante experiencias vividas, tomando como actores principales los sujetos inmersos en esta realidad. 


\section{Resultados}

Para el desarrollo de la investigación se hicieron uso de 4 metodologías las cuales a se describen a continuación.

Metodología 1. Actividad 1 - ronda vamos a jugar este zafarrancho

El juego representa la máxima representación de sentimientos de los infantes; ellos comunican las sensaciones, las acciones de ser, tener, hacer, coger, dar, amar, vivir, no cobran sentido comparten con el jardín, las plantas, el sol, el agua, las edades y el docente. Este juego permite que vivan experiencias y que conozcan el mundo que los rodea, crean su propia identidad y sus propias teorías.

Actividad 1. Ronda Vamos A Jugar Este Zafarrancho
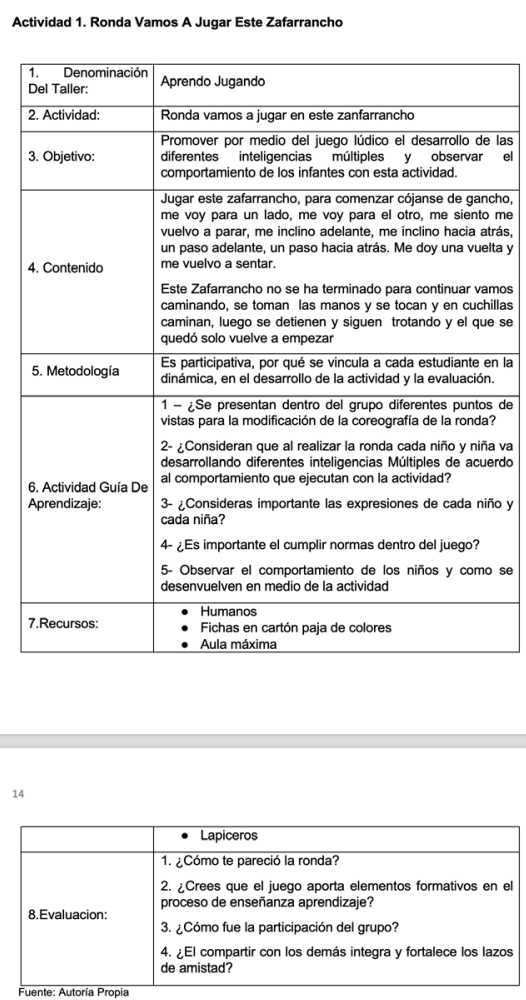

\section{Metodología 2}

Para la metodología 2 se desarrolló la actividad leyendo un cuento, realizando un recital, actividades de canto, actividad de limpieza del jardín, recorte de fotos con un grupo de (4) niños y armar un rompe cabezas de animales.

\section{Metodología 3}

Para la metodología 3 se describen las situaciones expuestas en la metodología (2) y se plantea ¿Cómo es el aprendizaje y la inteligencia múltiple?, las dificultades que obtuvieron los infantes al ejecutar la labor y se analiza cada actividad independiente.

\section{Metodología 4}

En la metodología 4 donde se analizan la Inteligencia Múltiple como constructor técnico emergente y los momentos 1, 2, 3, 4 y 5 que representan cada inteligencia desarrollados por los infantes. Se aplica la Investigación Descriptiva que posibilita un enfoque de acompañamiento y orienta a los infantes con sus propios recursos intelectuales, permite distintas formas de aprendizaje. Esta investigación con niños y niñas replantea la didáctica en función de la potencialización de las distintas inteligencias que contribuyan al logro del éxito de aquellas que son débiles en los niños y las niñas, ayuda a identificar a los infantes de acuerdo a su inteligencia y de esta manera trabaja distintas estrategias pedagógicas acorde a sus necesidades. La investigación aporta a la educación centrada en los individuos (infantes) exitosos y felices con sus saberes a nivel personal y académico. Los estudios descriptivos buscan especificar las propiedades importantes de personas, grupos o comunidad en este caso los Infantes de la Primera Infancia para un análisis donde se evalúan diversos aspectos de la inteligencia múltiple en las representaciones sociales y se 
miden de manera independiente - describir lo que se investiga.

Todos los instrumentos y técnicas permitieron el desarrollo de las diferentes inteligencias en los participantes y se valoran sus experiencias antes y después. De igual manera se trabajan diferentes actividades que permiten diferentes secciones de trabajo y se estimula la capacidad o habilidad de las inteligencias, esto se realizó con canto, poesías, fotografías, rompecabezas, instrumentos de limpieza. Se hizo uso de la observación para infantes con técnicas que permitan buscar el desarrollo de las diferentes inteligencias. De igual manera es notorio el progreso en la inteligencia lingüística, relacionada con las habilidades de escuchar cuentos, realizar recitales, se expresan adecuadamente, el interés para narrar historias, cuentos entre otros. La observación identifica las habilidades y características de los infantes para cada una de las inteligencias, lo mismo que al finalizar las experiencias.

Las variables son el tipo de inteligencias: Logica-Matematica, Lingüística, Espacial, Naturista, Intrapersonal.

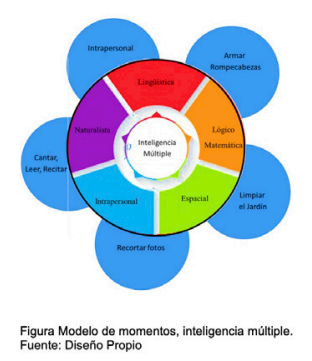

El momento 1 es el de Lingüística (desarrollo de la actividad leyendo un cuento, desarrollado un recital), el momento 2 naturista (limpiando el jardín), el momento 3 Intrapersonal (trabajo en grupo con el recorte de las fotos), el momento 4 Espacial (Recortando las fotos) y el momento 5 Lógico Matemática (armar el rompecabezas de animales).

\section{Resultados}

En la ronda el grupo los niños y niñas aprendieron a compartir sus opiniones, a respetar a sus compañeros, socializarse, relacionarse, tomar decisiones de manera responsable permitiendo fortalecer su desarrollo integral. En esta actividad trabaja el docente y el niño, se proporcionan recursos para la ejecución de la actividad y se comienza a fomentar la investigación múltiple y se estimula al infante.

Los resultados de la investigación descriptiva con la técnica de observación se obtuvieron de acuerdo a cada actividad a desarrollar por los infantes:

Algunos de los infantes leyeron cuentos, otros realizaron recitales, hubo otro grupo de canto y se observa que este último grupo tuvo dificultad para expresar en público sus sentimientos y mantener la mirada fija, la voz de canto es alta. Los infantes que realizaron el recital aunque no memorizaron todo sus expresiones verbales estas fueron claras y se observó la facilidad de la ejecución de la actividad en ellos y los infantes que leyeron, mas sin embargo se deben trabaja en las expresiones con las palabras para que mantenga la atención de los otros niños. De esta manera todos comparten sus expresiones en diferentes inteligencias, se observan que hay trabajo a fortalecer para estimular la creatividad creando historias, sosteniendo la atención en el grupo de compañeros, se requiere trabajar en la memoria y la integración grupal.

Armar el rompecabezas de animales (Lógica Matemática) evoluciona como son los objetos y cuál es el comportamiento en otras circunstancias; de manera inmediata no ubican las figuras, la destreza es baja pero en la medida que comienzan a tener confianza en el juego se interesan más por ser agiles y encontrar la figura adecuada, la secuencia de las imágenes es pausada hay que trabajar con ellos en la concordancia. 
Por otra parte en la actividad de recorte de fotos su motricidad no es perfecta, pero se esfuerzan por realizar los recortes y se debe trabajar en la destreza del cuerpo, del manejo de las herramientas con mayor facilidad, enseñando a alternar el orden de las figuras y utilizar el papel tridimensional.

La actividad de limpieza en el jardín genera en algunos rechazo a la arena y otros el juego con el agua, algunos se distraen, pero la actividad en los niños por el cuidado de las plantas es interesante como no es una actividad constante y es nuevo en el aprendizaje que se está desarrollando permite que sensibiliza la relación con el mundo natural, comienzan a desarrollar la capacidad para identificar las plantas, descubre la vegetación; se les enseña a identifica, describe y clasifica los elementos naturales. En estas actividades se desarrolla la intrapersonal donde se conectan y se es sensible; identifica y ayuda a conocer sus estados de ánimo y autoconocimiento y se descubre las emociones. Por otra parte La preparación de los docentes en conocimiento es importante de trabajar las inteligencias múltiples porque el docente debe saber cómo fortalecer la inteligencia múltiple de sus infantes desde temprana edad y la entidad debe actualizar al docente realizando capacitaciones permanentes en este tema porque el trabajo con los infantes es permanente y continuo. El docente fomenta el desarrollo de las inteligencia múltiple con las actividades de participación de parte de Él y otras actividades direccionadas por El, dando como resultado que el infante se desenvuelve en su día a día con más soltura y en su vida cotidiana con su entorno, se observa un trabajo constante con la escuela, docente y niños y niñas; se propicia el trabajo en conjunto y las experiencias de estas actividades sirven para analizar las características de cada uno y sus reacciones a las diferentes circunstancias.

\section{Conclusiones}

A modo de conclusión los docentes se deben involucrar cada día en el proceso educativo así como comprender el concepto de las inteligencias múltiples, saber cómo estimularlas en el aula de clases lo que ayudaría al infante a desarrollar su potencial y su desarrollo integral y aprendizaje significativo y coherente; es importante que el docente trabaje en mejorar el aprendizaje; darle más oportunidades al alumno y que desarrolle su talento mediante las actividades propuestas ; se pretende señalar la inteligencia que posee cada infante, en ese sentido se hace necesario que los niños aprenden de manera diferente, es importante que el docente lo capacite de varias formas y modos para que el infante entienda desde sus capacidades.

La inteligencia en la enseñanza permite al infante aprender más, tiene mejor dominio, que se destaque y se comprometa con el aprendizaje y disfrute mucho más las clases. Esto sirve para evaluar el contorno y el desempeño del alumno; porque todas las personas poseen inteligencia mayor o menor grado, suponemos que todos los niños son inteligentes de diversas maneras; cada uno tiene diferentes capacidades para desarrollar y estas inteligencias se estimulan de manera adecuada, pero esto es certero cuando se trabaja de manera constante y se realizan las evaluaciones Docente-Infante. 


\section{Referencias bibliográficas}

Araya, S. (2002). Las representaciones sociales: ejes teóricos para su discusión. Cuaderno de Ciencias Sociales 127. Facultad Latinoamericana de Ciencias Sociales. San José de Costa Rica, Costa Rica.

Cárdenas, A., \& Gómez, C. (2014). La literatura en la educación inicial. Obtenido de https:// aprende.colombiaaprende.edu.col

Cova, C., \& Ernesto, C. (2013). Estrategias de enseñanza y de aprendizaje empleadas por los (as) docentes de matemáticas y su incidencia en el rendimiento académico de los (as) estudiantes de 4to año del liceo bolivariano "Creación Cantarrana" período 2011-2012, Cumaná Estado Sucre (Doctoral dissertation, Universidad de Oriente)

Gardner, H. (1998). A multiplicity of intelligences. Scientific American, 9(4), 19-23.

Gardner, H. (1994). Estructuras de la mente. Las inteligencias múltiples. Madrid, España: Fondo de la cultura economica, USA.

Gardner, H. (2016). Estructuras de la mente: la teoría de las inteligencias múltiples. Fondo de cultura económica.

Gonza, F., \& Chumacero. (2019). El juego como símbolo de la infancia: Miradas de estudiantes de psicología y psicopedagogía. Difusiones, 178-189.

Hernández, R., Fernández, C., \& Baptista, P. (2010). Metodología de la investigación (5th ed.). México D.F: Mc Graw Hill.

Montes de Oca Recio, N., \& Machado Ramírez, E. F. (2011). Estrategias docentes y métodos de enseñanza-aprendizaje en la Educación Superior. Humanidades médicas, 11(3), 475-488.

Moscovici, S. (1979). El psicoanálisis, su imagen y su público. Editorial huemul.

Saldaña, L. (2014). Estrategias de aprendizaje, motivación y rendimiento académico en alumnos de nivel medio superior. Obtencion del grado de maestria.

Sautu, R., Boniolo, P., Dalle, P., \& Elbert, R. (2005). Manual de metodología: construcción del marco teórico, formulación de los objetivos y elección de la metodología. 